\title{
Laboreal
}

Volume $16 \mathrm{~N}^{\circ} 2$ | 2020

Programa de Pesquisa do Curso da Ação

\section{A reconstrução do trabalho docente pela participação ativa e constante do professor no processo de (co)análise da própria atividade}

La reconstrucción del trabajo docente a través de la participación activa y constante del profesor en el proceso de (co)análisis de la propia actividad La reconstruction du travail enseignant par la participation active et continue du professeur dans le processus de (co)analyse de sa propre activité Teacher work reconstruction through active and constant participation of the teacher in the (co)analytical process of his own activity

\section{Elisandra Maria Magalhães e Daniel Faïta}

\section{OpenEdition}

\section{Journals}

\section{Edição electrónica}

URL: http://journals.openedition.org/laboreal/17243

DOI: $10.4000 /$ laboreal. 17243

ISSN: 1646-5237

Editora

Universidade do Porto

\section{Refêrencia eletrónica}

Elisandra Maria Magalhães e Daniel Faïta, « A reconstrução do trabalho docente pela participação ativa e constante do professor no processo de (co)análise da própria atividade », Laboreal [Online] Volume 16 No2 | 2020, posto online no dia 01 dezembro 2020, consultado o 14 dezembro 2020. URL http://journals.openedition.org/laboreal/17243; DOI : https://doi.org/10.4000/laboreal.17243

Este documento foi criado de forma automática no dia 14 dezembro 2020

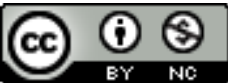

Laboreal está licenciado com uma Licença Creative Commons - Atribuição-NãoComercial 4.0 Internacional. 


\section{A reconstrução do trabalho docente pela participação ativa e constante do professor no processo de (co)análise da própria atividade}

La reconstrucción del trabajo docente a través de la participación activa y constante del profesor en el proceso de (co)análisis de la propia actividad La reconstruction du travail enseignant par la participation active et continue du professeur dans le processus de (co)analyse de sa propre activité Teacher work reconstruction through active and constant participation of the teacher in the (co)analytical process of his own activity

Elisandra Maria Magalhães e Daniel Faïta

\section{NOTA DO EDITOR}

Manuscrito recebido em: 24.03 .2020

Aceite após peritagem em: 17.10 .2020

\section{Introdução}

1 Este trabalho propõe-se a apresentar o processo metodológico adotado numa pesquisa de doutorado (Magalhães, 2019) que teve como objetivo principal realizar uma análise dialógica da atividade linguageira de dois professores formadores das línguas inglesa e espanhola da Universidade Estadual do Ceará (UECE) - antes e após uma intervenção clínica e ergonômica da atividade - para uma reflexão sobre as implicações discursivas e didático-pedagógicas dessa intervenção na atividade linguageira desses professores 
formadores e, potencialmente, na formação inicial de futuros professores de língua estrangeira [1].

2 A questão mais geral, que norteou todo o estudo realizado, foi: Quais seriam as implicações discursivas e didático-pedagógicas de uma intervenção clínica e ergonômica da atividade para a transformação da atividade linguageira dos professores formadores e de seu próprio agir formativo? Tal questão orientou as três questões específicas de pesquisa: 1. Como acontece a atual formação inicial de futuros professores em aulas teóricas e em aulas de prática de ensino de línguas inglesa e espanhola?; 2. Como se constrói a atividade dos professores formadores em sala de aula?; 3. Como se apresenta a atividade (concreta e/ou linguageira) dos professores formadores em disciplinas teóricas e de prática de ensino e em licenciaturas de duas diferentes línguas?

3 No concernente às inquietações apresentadas na pesquisa, o que mais particularmente preocupava Magalhães (2019) - além do (ainda) reduzido número de pesquisas feitas com professores formadores de língua estrangeira dentro das perspectivas clínica e ergonômica da atividade - era o fato de não haver estudos sobre formação inicial em diferentes cursos de licenciatura em língua estrangeira; estudos que levassem em consideração a teoria e a prática docente e que privilegiassem o diálogo entre essas dimensões bem como entre os próprios profissionais formadores.

4 A pesquisadora coloca que romper com essa ausência de diálogo entre cursos de diferentes línguas, entre disciplinas de teoria e de prática de ensino, entre pares formadores e entre professor formador e sua própria atividade, pode ser um passo em direção a uma postura formativa mais sociotransformadora. Ou seja, cada professor formador pode passar a entender seu(s) colega(s) de trabalho, seu(s) aluno(s), sua própria atividade ou até ele mesmo e suas próprias experiências docentes (presentes e/ ou passadas) como essenciais no processo de formação de futuros professores de língua estrangeira.

5 Os estudos ergonômicos da atividade e a abordagem clínica da atividade favorecem esse diálogo do profissional com ele mesmo e com "o outro" (o profissional como um "outro" de si mesmo, o(s) seu(s) par(es) profissional(ais), o analista externo, o coletivo de trabalho, etc.) através de um quadro clínico-desenvolvimental (Clot, 2008) denominado autoconfrontação, o qual, segundo Faïta e Maggi (2007), permite que o sujeito (re)formule suas próprias interrogações e (re)mobilize seus saberes para a compreensão e a transformação de suas próprias situações de trabalho.

6 Seguindo a perspectiva ergonômica e clínica da atividade, a pesquisadora optou pela autoconfrontação como dispositivo teórico-metodológico e recorreu aos princípios da Ergonomia da Atividade e da Clínica da Atividade para analisar e compreender juntamente com os próprios profissionais implicados no processo da pesquisa - o trabalho docente realizado no contexto da formação inicial de professores de língua estrangeira dos cursos de Letras/Inglês e Letras/Espanhol da UECE.

7 O objetivo era fazer emergir, a partir das verbalizações de cada professor formador sobre sua própria atividade docente, o real de seu trabalho (Clot, 2008); autorizando-o, assim, a '“conceber' e 'reconstruir' suas ações [e/ou as ações de seu par profissional] dentro de outras perspectivas" (Félix \& Saujat, 2007, p. 6, tradução livre). Daí, foi possível cogitar mudanças na atual formação inicial de professores de língua estrangeira, já que esta passa inevitavelmente pela atividade docente e linguageira dos próprios professores formadores [2욤. 
Embora este artigo objetive apresentar o processo metodológico adotado na pesquisa de doutorado de Magalhães (2019), entendemos como necessário trazer, na seção que segue, os aportes teóricos que guiaram e fundamentaram a pesquisa como um todo, ou seja, dentro de um quadro mais amplo e geral do estudo.

\section{Referencial teórico}

Desde o início dos anos 2000, quando foi introduzido no Brasil o estudo das relações entre linguagem e trabalho educacional, inúmeras pesquisas sobre o assunto foram feitas no âmbito da Linguística Aplicada e dos Estudos da Linguagem, muitas voltadas para o agir do professor em situação de trabalho, isto é, o "agir tal como textualizado pelo professor em seu próprio discurso" (Machado, 2004, p. xix).

10 O pensamento de Bakhtin (2011, 2015), Bakhtin e Volochínov (2010), Voloshinov e Bakhtin (1976) e Vigotski (1998a, 1998b) influenciam fortemente os trabalhos dos pesquisadores que estudam as atividades educacionais como trabalho e as relações dialógicas que se instauram entre profissional/pesquisador, profissional/ele próprio, profissional/par, profissional/própria atividade, profissional/métier, etc. Nesse enfoque, tais relações dialógicas, suscitadas no momento das trocas verbais, podem ser entendidas como a base para a transformação (do) profissional.

11 É necessário lembrar que a Ergonomia da Atividade redireciona o entendimento do que é trabalho e instaura a atividade profissional e linguageira do trabalhador como unidade de análise, englobando também, assim como a postura adotada pela Clínica da Atividade, as dimensões subjetivas do sujeito.

12 Segundo Amigues (2003, p. 6, tradução livre), a abordagem ergonômica da atividade levanta questões a respeito da "(...) variabilidade das situações de trabalho e [d]a importância das dimensões subjetivas" e Clot (2006, p. 105) postula que a Clínica da Atividade "é um dispositivo clínico utilizado para pesquisar o que não foi realizado, para restaurar o possível da atividade, para ver e mostrar o que não é possível". A Clínica da Atividade sustenta que se deve fazer da atividade passada objeto da atividade presente através de comentários e avaliações entre os sujeitos envolvidos. Conforme apontam Darses e Montmollin (2006, p. 55, tradução livre),

A observação é às vezes insuficiente à análise do trabalho (...). É por isso que é necessário, em numerosas situações, produzir dados complementares aos fornecidos pelo comportamento visível e explícito. Utilizam-se então técnicas cujo objetivo é de fazer falar as pessoas a respeito de seu trabalho.

Nessa perspectiva, o linguista e pesquisador das situações de trabalho, Daniel Faïta, propõe, no final dos anos 1980, o quadro teórico-metodológico da autoconfrontação que favorece a verbalização do trabalhador e o leva a ser o principal analista de sua atividade.

Pareceu-nos, então, justificável realizar a gravação de um vídeo sobre cada umas das funções de trabalho determinantes para, em seguida, submeter os documentos produzidos aos trabalhadores interessados, pedindo-lhes para comentar sua própria atividade. (Faïta, 1989, p. 116, tradução livre). 
Assim, a pesquisa aqui exposta - fundamentada em áreas que pensam o trabalho (Ergonomia da Atividade e Clínica da Atividade), no quadro teórico-metodológico da autoconfrontação, bem como em questões de ordem psicológica (teoria históricocultural vigotskiana) e de estudo da linguagem (filosofia bakhtiniana) - buscou (co)analisar e compreender, juntamente com os profissionais envolvidos, as atividades docente e linguageira de dois professores formadores de língua estrangeira da UECE.

Destacamos que o quadro teórico-metodológico da autoconfrontação não se propõe a ser "(...) uma técnica repetitiva de coleta de dados verbais, submetidos, na sequência, aos procedimentos de análise próprios a cada disciplina (...)" (Faïta, 2012, p. 89, tradução livre). Com efeito, em se tratando de um processo e não de um produto, a autoconfrontação objetiva criar as condições propícias para a instauração de diversos diálogos profissionais a respeito das dimensões observáveis e inobserváveis da atividade de trabalho dos profissionais de um determinado meio laborativo.

O propósito basilar da autoconfrontação é fazer com que esses diálogos evoluam e, por conseguinte, auxiliem na transformação da atividade do profissional no momento mesmo da tessitura dialógica engendrada pelo próprio processo autoconfrontativo. Essa tessitura dialógica se liga nitidamente à atividade passada, presente e futura do trabalhador. Afinal, como destacam John-Steiner e Souberman (1998, p. 169), baseados na teoria vigotskiana do desenvolvimento das funções superiores tipicamente humanas,

A fala humana é, de longe, o comportamento de uso de signos mais importante ao longo do desenvolvimento da criança. Através da fala, a criança supera as limitações imediatas de seu ambiente. Ela se prepara para a atividade futura; planeja, ordena e controla o próprio comportamento e o dos outros (...).

Podemos, portanto, dizer que o quadro teórico-metodológico da autoconfrontação, na pesquisa que aqui apresentamos, ultrapassou os métodos reflexivos de produção de conhecimento sobre o próprio trabalho, pois, enquanto processo histórico, social, dialógico, (co)analítico e interativo, ele permitiu e possibilitou que o profissional levasse em consideração o "outro" e, evidentemente, a fala do "outro" (esse "outro" pode ser ele mesmo extraposicionado [3: o seu par profissional, a pesquisadora, o coletivo de trabalho, etc.) como seus parceiros em direção a um desenvolvimento profissional. A esse respeito Vigotski (1998b, p. 89) afirma que

A análise introspectiva, na qual observadores altamente treinados são instruídos a notar todos os aspectos da sua própria experiência consciente, não pode levar-nos muito longe. (...). Deve ficar claro que a análise introspectiva não fornece a explicação dinâmica ou causal real de um processo (...).

Sendo entendido como um processo, o quadro teórico-metodológico da autoconfrontação, na pesquisa de Magalhães (2019), não foi conjecturado como algo inerte, finito e linear, muito pelo contrário, ele foi entendido como algo dinâmico, inconcluso e, mesmo, sinuoso.

Ressaltamos que mudar comportamentos, atitudes, hábitos, estratégias, etc., na vivência sociolaborativa quotidiana, não é algo simples e nem fleumático. Vigotski 
(1998b) chega mesmo a afirmar que o caráter automático das formas fossilizadas de comportamento cria grandes dificuldades para uma análise psicológica.

Em relação à pesquisa aqui apresentada, cabe dizer que as condutas automatizadas dos professores formadores poderiam ter sido um problema para a pesquisadora, pois os próprios profissionais, não obrigatoriamente, sentiam a necessidade de mudança(s) em suas práticas docentes. E daí a importância da interação com o "outro" (ele mesmo como "outro" de si, o par profissional, a pesquisadora, o coletivo, etc.) e das relações dialógicas (Bakhtin, 2015) que se estabeleceram entre os vários momentos da atividade (presente, passada e futura) desses profissionais.

21 Sobre a importância da interação com o "outro" na e para a análise do trabalho, abordamos, na seção a seguir, os passos metodológicos que foram adotados para a (co)construção do corpus discursivo da pesquisa em questão.

\section{Processo metodológico}

O estudo de Magalhães (2019) pôs em foco o trabalho do professor formador e sua atividade linguageira sobre este trabalho na formação inicial de futuros professores de língua estrangeira, no confronto e nas trocas verbais com a pesquisadora e com um par profissional. $\mathrm{O}$ contexto constituiu-se de dois cursos de licenciatura em língua estrangeira da UECE: Letras/Inglês e Letras/Espanhol.

Os dois professores formadores, sujeitos da pesquisa, por estarem ministrando disciplinas teóricas e de prática de ensino em línguas inglesa e espanhola no segundo semestre letivo de 2017, foram convidados pela pesquisadora, dentre os demais professores pertencentes ao coletivo profissional das duas licenciaturas, para participar da pesquisa.

Desse modo, integraram o campo de investigação as seguintes disciplinas dos cursos de Letras/Inglês e de Letras/Espanhol da UECE: 1. Produção Escrita em Língua Espanhola (disciplina ministrada no sexto semestre do curso), 2. Estágio Supervisionado IV em Língua Espanhola (disciplina ministrada no oitavo semestre do curso), 3. Leitura em Língua Inglesa (disciplina ministrada no primeiro semestre do curso) e 4. Estágio Supervisionado I em Língua Inglesa (disciplina ministrada no sexto semestre do curso).

Foram, portanto, contempladas disciplinas que atingiam entre o primeiro e o oitavo semestres dos cursos de Letras/Inglês e Letras/Espanhol da UECE; o que fez com que a pesquisa apresentasse uma visão mais abrangente das etapas (teóricas e de prática de ensino) que constituem a formação inicial vigente nos dois mencionados cursos de licenciatura.

Sobre a autoconfrontação, resumimos, à luz de Clot e Faïta (2000/2016), as fases que a compõem: 1) constituição do grupo de profissionais que participará do processo; 2) gravações em vídeo das atividades de trabalho, previamente selecionadas, desses profissionais; 3) autoconfrontação simples, durante a qual o profissional, diante do pesquisador, é confrontado às imagens de sua própria atividade, fazendo, destarte, comentários a respeito da mesma; 4) autoconfrontação cruzada, a partir da qual o profissional, em presença do analista externo e de um par profissional, é confrontado à gravação da atividade de trabalho deste par, bem como, por mais uma vez, à sua própria atividade, fazendo comentários e questionando ambas as atividades; e 5) 
extensão da análise que foi produzida pelos profissionais protagonistas do processo ao coletivo de trabalho.

A pesquisa que apresentamos não seguiu todas essas fases propostas pelo quadro teórico-metodológico da autoconfrontação, a pesquisadora achou necessário realizar algumas adaptações. Como exemplo, mencionamos a inserção de uma formação continuada composta de 10 horas/aula pautada nos princípios clínicos e ergonômicos da atividade. Essa formação foi proposta aos dois professores formadores como parte do processo para a (co)construção do corpus de estudo.

A esse respeito, Magalhães (2019) entende a autoconfrontação como um quadro teóricometodológico muito particular de investigação e análise da atividade linguageira do sujeito a partir da situação concreta de trabalho e que, ainda, encontra-se em processo de exploração e desenvolvimento, revelando-se, assim, muito flexível em relação à sua apropriação, às adaptações possíveis e aos procedimentos de análise. Isso, sem esquecer que a autoconfrontação não é, e nem intenciona ser, segundo a própria pesquisadora, um modelo de conduta a ser seguido à risca por aqueles - psicólogos, ergonomistas, linguistas, etc. - que a adotam. Para Faïta e Maggi (2007, p. 26, tradução livre),

O traço distintivo da metodologia da autoconfrontação é o de instaurar um conjunto de relações dialógicas (...). Nunca será o bastante lembrar que se trata de um processo (...). (...) não é um procedimento de coleta de dados, e menos ainda um meio de fazer as pessoas falarem o que se quer ouvir!

Havendo, portanto, optado pelo quadro teórico-metodológico da autoconfrontação, a pesquisa em questão, está alicerçada fortemente nos princípios e conceitos bakhtinianos quanto à concepção da linguagem, bem como na psicologia históricocultural vigotskiana sobre o desenvolvimento humano. Isso fez com que a pesquisadora adotasse uma maneira muito particular de entender a natureza desse "método indireto" (Vigotski, 1998b) de investigação e (co)análise que é o quadro teóricometodológico da autoconfrontação.

Nessa perspectiva, a pesquisadora efetuou uma transcrição e uma análise minuciosas das verbalizações dos dois professores formadores em todos os momentos que constituíram o processo de produção do corpus discursivo para, em seguida, realizar uma interpretação dos "traços" linguageiros (Clot, 2011, p. 20) que foram mobilizados ou deixados pelo caminho pelos profissionais durante (e para) a construção da própria atividade de trabalho e durante (e para) a "'reduplicação' da [sua] experiência vivida" (Clot, 2011, p. 19).

31 Traços, esses, que sinalizaram transformações, estranhamentos, rupturas, avanços, contradições, conflitos, etc., entre a atividade realizada e o que os professores formadores diziam sobre a própria atividade. Substancialmente, foi a partir das verbalizações dos professores formadores e de suas próprias perspectivas que foi realizada uma interpretação desses traços e, ainda, de seu olhar extraposicionado (Bakhtin, 2011) em relação a si mesmo e à sua atividade formativa no decorrer do processo autoconfrontativo.

Desse modo, as inúmeras e multifacetadas teias dialógicas estabelecidas foram confrontadas - "(...) entre as situações sucessivas, entre um agente, ele mesmo, e o observador, depois entre esse mesmo agente e um par, etc." (Faïta \& Maggi, 2007, p. 26, tradução livre) - com os fundamentos teóricos e metodológicos que norteiam as 
abordagens clínica e ergonômica da atividade para, então, serem compreendidos os fenômenos emersos desse embate.

A pesquisadora realizou, no decorrer do processo da pesquisa, uma interpretação a partir de uma outra interpretação, ou seja, ela buscou interpretar a interpretação que os professores formadores fizeram em autoconfrontação (simples e cruzada), bem como durante a formação de 10h/a que lhes foi proposta, sobre suas passadas, atuais e/ou futuras práticas formativas. Vale ressaltar que o objetivo não era apenas uma interpretação do antes (práticas passadas), do atual (práticas presentes) e do depois (práticas futuras), mas também do próprio movimento realizado pelos profissionais no interior mesmo de suas histórias pessoal e profissional.

Entendemos que, por ter atuado diretamente na formação (inicial e continuada) de professores (em formação e enquanto já formadores), a pesquisa em questão configurase como interventiva [ ${ }^{4}$. Primeiramente, porque a pesquisadora entrou na sala de aula de dois professores formadores para observar e filmar suas atividades docentes; em seguida, porque suscitou, durante as autoconfrontações (simples e cruzada), um diálogo (co)analítico de cada professor formador com ele mesmo, com seu trabalho, com seu par profissional e com o trabalho deste; e por último, porque realizou, juntamente com os dois professores formadores, uma formação de três dias durante a qual lhes propôs a partir das filmagens de suas próprias atividades docentes - alguns dos fundamentos teóricos e metodológicos que alicerçam os estudos clínicos e ergonômicos da atividade.

35 A nosso ver, todos os movimentos dialógicos, (co)analíticos, interventivos, confrontativos e interpretativos que foram desencadeados para a realização da pesquisa configuram-se dentro de uma perspectiva dialógica da linguagem, ou seja, esses movimentos não têm um término definido a priori (Bakhtin, 2015). Em outros termos, esse processo dialógico iniciado - e mantido - pelo quadro teóricometodológico da autoconfrontação não foi limitado a um tempo e a um espaço determinados.

36 A propósito do corpus discursivo (co)construído durante o processo autoconfrontativo, ele foi composto das respostas dadas pelos dois professores formadores à uma entrevista oral gravada individualmente em áudio, de diálogos de quatro autoconfrontações simples e de diálogos de uma autoconfrontação cruzada realizadas sobre suas próprias situações concretas de trabalho em disciplinas teóricas e de prática de ensino de línguas inglesa e espanhola; além de alguns enunciados dessas situações concretas em sala de aula de cada professor formador. Os diálogos produzidos durante a formação de 10 horas - sustentada pelos princípios clínicos e ergonômicos da atividade com os dois professores formadores - também compuseram o corpus de estudo.

37 Acrescentamos que as análises e interpretações desse corpus discursivo foram realizadas dentro de uma perspectiva dialógica em oposição a uma perspectiva linguística stricto sensu. Dizendo com outras palavras, foram levados em consideração não apenas fatores puramente linguísticos (gramaticais, morfológicos e/ou sintáticos), mas também fatores metalinguísticos (Bakhtin, 2015) permitindo, assim, que o corpus pudesse fazer emergir suas formas próprias de produzir sentido, haja vista as categorias linguísticas não serem suficientes quando se trata de interação socioverbal (Voloshinov \& Bakhtin, 1976; Bakhtin \& Volochínov, 2010; Bakhtin, 2015).

38 Afinal, como assinalam Sobral e Giacomelli (2018), a compreensão do todo do discurso tanto as marcas linguísticas quanto as marcas enunciativas que mobilizaram um dado 
material [5] - é vital para uma análise dialógica (ou Metalinguística) na perspectiva bakhtiniana (Bakhtin, 2015). Sobre isso, Voloshinov e Bakhtin (1976, p. 9) afirmam que

O enunciado concreto (e não a abstração linguística) nasce, vive e morre no processo da interação social entre participantes da enunciação.

(...)

O significado e a importância de um enunciado na vida (seja qual for a espécie particular deste enunciado) não coincide com a composição puramente verbal do enunciado.

Seguindo essa perspectiva, somente após a organização de todos os diálogos (co)produzidos durante o processo da pesquisa, e apenas a partir de uma leitura atenta e acurada de tais diálogos, a pesquisadora pôde realizar uma análise das relações estabelecidas entre a materialidade linguística (nível micro) e as características enunciativas (nível macro), de tal modo que, fundamentada nessas relações, a interpretação dos sentidos produzidos pelos enunciados concretos dos sujeitos se deu. Nas palavras de Sobral e Giacomelli (2018, p. 313), “(...) as teorias bakhtinianas revelam que só um tratamento abrangente, transdisciplinar, dos fenômenos é capaz de fazer justiça à complexidade do ser, do agir e do significar dos seres humanos".

Ainda a respeito da (co)construção do corpus discursivo, o primeiro momento de todo o processo foi entrar em contato com dois professores formadores dos cursos de Letras/ Inglês e Letras/Espanhol da UECE que ministravam disciplinas teóricas e de prática de ensino no segundo semestre letivo de 2017. Em um segundo momento, ocorreram as observações das aulas desses professores e algumas anotações foram realizadas durante as observações, no entanto, nenhuma delas compôs o corpus de estudo da pesquisa. Foram anotações mais gerais sobre o espaço da sala de aula, as disciplinas ministradas, o cronograma disponibilizado aos alunos, as informações gerais sobre o curso e o material a ser utilizado durante o segundo semestre letivo de 2017.

41 Após as observações, deu-se o terceiro momento do processo para a (co)construção do corpus: a realização de duas entrevistas orais gravadas em áudio, ou seja, uma entrevista com cada professor formador. Essas entrevistas auxiliaram no entendimento de quem são os dois professores formadores. Mais especificamente, cada professor formador discorreu, de forma sucinta, sobre: 1. sua formação (inicial e continuada); 2. sua(s) experiência(s) como formadores de professores; 3. suas condições de trabalho; 4. suas dificuldades como formadores e, por fim; 5 . as ementas das disciplinas teóricas e de prática de ensino que compõem os currículos dos cursos de Letras/Inglês e Letras/ Espanhol da UECE.

42 Tais entrevistas foram realizadas individualmente e de forma semidirigida, ou seja, sem imposição de perguntas. Embora houvesse um esquema inicial básico, a pesquisadora não o aplicou com rigidez. Esse terceiro momento foi considerado como uma etapa complementar dentro do processo interventivo habitual do quadro teóricometodológico da autoconfrontação pautado em princípios dialógicos e sócio-históricos.

Após as entrevistas, foram efetuadas as primeiras filmagens das aulas dos professores formadores para a realização das primeiras autoconfrontações simples. A partir dessas filmagens, a pesquisadora efetuou a seleção e a edição de algumas sequências de situações concretas de aula para a realização da primeira autoconfrontação simples com cada professor formador [ $\left.{ }^{6}\right]$. Esse momento visou à produção de dois curtos vídeos 
- um para cada professor formador - que uniram excertos de suas duas aulas filmadas e que, por conseguinte, deveriam suscitar verbalizações sobre suas atividades de trabalho.

Essas sequências de situações concretas de aula buscaram evocar comentários de cada um dos professores formadores que elucidassem aspectos pertinentes às suas atividades concretas de trabalho, ou seja, às suas práticas docentes na formação de futuros professores das línguas inglesa e espanhola.

Em seguida, no quinto momento do processo, uma autoconfrontação simples foi realizada com cada professor formador. O objetivo nesse momento foi criar um espaço no qual os professores formadores pudessem dialogar com sua atividade formativa, com eles mesmos e com a pesquisadora a partir das imagens gravadas de suas aulas.

Posteriormente a essas primeiras autoconfrontações simples, ocorreu uma formação de 10 horas - 0 ensino como trabalho - sustentada pelos princípios clínicos e ergonômicos da atividade com os dois professores formadores [7]. Essa formação objetivou propor aos professores formadores, a partir dos vídeos de suas próprias atividades, alguns dos fundamentos teóricos e metodológicos que alicerçam os estudos clínicos e ergonômicos da atividade [8].

47 A exposição desses princípios teóricos e metodológicos (10 horas de formação) se deu por meio de slides que, partindo das aulas filmadas de cada professor formador, traziam para discussão textos de autores que realizaram estudos no âmbito da Ergonomia da Atividade e/ou da Clínica da Atividade.

Para essa formação, a pesquisadora utilizou o próprio material gravado das atividades realizadas em salas de aula. Nessa direção, cenas das aulas gravadas de cada professor formador foram selecionadas e submetidas à discussão durante a formação, com o fito de apoiar-se na própria prática docente dos professores formadores para, então, introduzir alguns dos fundamentos teóricos e metodológicos utilizados na Ergonomia da Atividade e na Clínica da Atividade. Os três dias de formação foram gravados em vídeo, os diálogos produzidos foram transcritos e serviram como parte do corpus de estudo.

Ressaltamos que o objetivo da formação $O$ ensino como trabalho não corresponde aos objetivos de nenhuma das autoconfrontações (simples e cruzada) realizadas. A pesquisadora, no decorrer dessa formação, além de pesquisadora também atuava como formadora, haja vista ter se tratado de uma formação continuada que foi proposta aos sujeitos da pesquisa e cujo objetivo central era introduzir e discutir alguns dos pressupostos teóricos e metodológicos provenientes da Ergonomia da Atividade e da Clínica da Atividade a partir de imagens que foram gravadas das aulas de cada professor formador.

50 Para a formação continuada, a pesquisadora partiu da atividade concreta de cada professor formador em sala de aula, isto é, cada atividade concreta selecionada precedeu, guiou e amparou a introdução dos pressupostos teórico-metodológicos apresentados durante a formação. Afinal, como afirma Bakhtin (2011, p. 198), “(...) para objetivar e concluir a consciência do outro, nunca se utilizar de nada que seja inacessível a essa mesma consciência, que esteja fora dos seus horizontes."

51 Na ocasião do primeiro dia de formação, foram apresentadas aos dois professores formadores duas sequências da aula de Estágio Supervisionado I em Língua Inglesa e duas sequências da aula de Estágio Supervisionado IV em Língua Espanhola. O objetivo, neste dia, 
era partir das imagens das aulas dos dois professores formadores para explorar o texto Trabalho do professor e trabalho de ensino (Amigues, 2004) e os aportes teóricos ali apresentados e discutidos, a saber: a abordagem ergonômica da atividade docente, o trabalho prescrito, o trabalho realizado, a tarefa, a atividade, o real da atividade, entre outros. No segundo dia da formação, a pesquisadora apresentou aos dois professores formadores duas cenas da aula de Leitura em Língua Inglesa, uma da aula de Produção Escrita em Língua Espanhola e uma da aula de Estágio Supervisionado I em Língua Inglesa. 0 objetivo era iniciar a discussão a partir de situações concretas de sala de aula para introduzir as noções de: o gênero da atividade, o estilo profissional, a compreensão para a transformação, a transformação para a compreensão, a abordagem clínica da atividade, entre outras noções.

Todo esse arcabouço teórico apresentado no segundo dia da formação apoiava-se nas imagens das aulas dos dois professores formadores e nos textos de Amigues (2004) e de Souza-e-Silva (2004). Ao final, como atividade extraclasse, os professores formadores receberam os textos Autoconfrontação simples (ACS): um instrumento de formação docente (Magalhães \& Moraes, 2016) e Abordagem clínica na análise da atividade docente: uma via unindo pesquisa, intervenção e formação (Moraes \& Magalhães, 2017) para serem discutidos no último dia de encontro.

O terceiro e último dia da formação teve como material desencadeador das discussões que foram estabelecidas duas sequências da aula de Estágio Supervisionado I em Língua Inglesa, uma da aula de Produção Escrita em Língua Espanhola e uma da aula de Estágio Supervisionado IV em Língua Espanhola. Neste dia, o objetivo era apresentar e discutir (sobre): as verbalizações dos trabalhadores sobre o próprio trabalho, a insuficiência das observações para a compreensão do real da atividade, o quadro teórico-metodológico da autoconfrontação, a importância do outro na construção do conhecimento, entre outros assuntos. Assim como nos dois outros dias de formação, todas as explanações teóricas desenvolvidas tiveram origem na própria cena da atividade concreta dos dois professores formadores em suas salas de aula.

Posteriormente à formação proposta aos dois professores formadores, foi realizado um segundo momento de filmagens de situações concretas de trabalho docente, ou seja, mais uma aula de uma disciplina teórica e mais uma aula de uma disciplina de prática de ensino de cada professor formador foram gravadas em vídeo.

Em seguida, foi efetuada mais uma autoconfrontação simples com cada professor formador. Para esse segundo momento de autoconfrontação simples, foi solicitado aos dois professores formadores que assistissem, na íntegra, as suas duas últimas aulas filmadas (uma aula de uma disciplina teórica e uma aula de prática de ensino) e selecionassem uma sequência de cada aula para a realização dessa segunda autoconfrontação simples.

57 A escolha foi limitada a uma sequência de cada aula (uma aula de uma disciplina teórica e uma aula de prática de ensino) porque a pesquisadora também deveria selecionar sequências para serem visualizadas e comentadas por cada professor formador. Nesse momento da escolha das sequências, a pesquisadora deu as seguintes instruções aos professores formadores: 1 . apenas uma sequência de cada aula deve ser selecionada; 2 . cada sequência pode ter o tempo que for necessário; e 3. as duas sequências devem ser significativas, levando em consideração todo o processo da pesquisa. Percebemos, aqui, 
um trabalho em conjunto e, por conseguinte, (co)analítico entre os sujeitos da pesquisa e a própria pesquisadora.

58 A pesquisadora buscou, durante a segunda autoconfrontação simples, perceber possíveis modificações nas atividades docentes dos professores formadores e/ou em suas atividades linguageiras após o processo inicial da pesquisa. Dito de outro modo, o objetivo foi verificar se a teoria - havendo sido apresentada durante a formação continuada a partir da própria experiência concreta e/ou linguageira de cada professor formador - foi melhor compreendida a ponto de levar os dois profissionais a pensar em uma transformação de suas práticas na formação inicial de professores das línguas inglesa e espanhola da UECE.

59 Nesse momento do processo, foi possível constatar o quanto os princípios da Ergonomia da Atividade e da Clínica da Atividade - quando estas evocam a ideia de "compreender para transformar" e de "transformar para compreender", respectivamente - estão correlacionados.

60 Com efeito, foi transformando as relações entre profissionais e analista externo (pesquisadora), bem como entre profissionais e teorias que fundamentam a análise da atividade que a pesquisadora conseguiu melhor compreender, juntamente com cada professor formador, a atividade docente destes últimos na formação inicial. Vale acrescentar que foi a partir dessa compreensão que os dois professores formadores puderam projetar (linguageiramente) transformações em suas atividades futuras.

61 Após o segundo momento de autoconfrontação simples, houve a realização de uma autoconfrontação cruzada. Nesse momento do processo, foi criado um espaço de encontro e diálogo entre pares profissionais (professor formador de espanhol e professora formadora de inglês) no qual lhes foi permitido colocar em questão o trabalho um do outro e, por mais uma vez, observar e analisar o seu próprio trabalho.

Para isso, foi levado para a realização da autoconfrontação cruzada um vídeo com imagens selecionadas pela pesquisadora das oito aulas gravadas (quatro aulas filmadas antes da formação $O$ ensino como trabalho e quatro aulas filmadas pós-formação), bem como imagens das quatro autoconfrontações simples realizadas com os dois profissionais (duas autoconfrontações simples pré-formação e duas autoconfrontações simples pós-formação com cada professor formador).

63 O vídeo com essas imagens apresentava treze sequências de situações concretas de sala de aula de cada um dos professores formadores com seus respectivos comentários produzidos durante as autoconfrontações simples. As treze sequências que integravam o vídeo foram organizadas, pela pesquisadora, por temáticas que pudessem viabilizar uma discussão (em linhas gerais) consonante e/ou dissonante entre os dois professores formadores a respeito de suas práticas formativas ou de suas atividades linguageiras sobre suas práticas formativas.

64 A escolha dessas temáticas foi estabelecida de forma que pudesse alcançar o objetivo definido para este momento da pesquisa, isto é, promover uma situação de trocas e diálogos, divergentes e/ou convergentes com os sujeitos da pesquisa sobre as suas situações concretas de trabalho (e de seu par profissional) e sobre os seus comentários em autoconfrontação simples (e de seu par profissional) a respeito dessas situações.

65 A autoconfrontação cruzada, ao final do processo para a (co)construção do corpus discursivo, mostrou-se oportuna para engendrar um diálogo amplo, contínuo e complexo entre os dois professores formadores sobre as situações concretas de suas 
próprias aulas (bem como sobre aquelas de seu par profissional) e os comentários que eles desenvolveram a partir dessas situações em autoconfrontação simples [ $\left.{ }^{[}\right]$.

Nesse processo autoconfrontativo (simples e cruzado) - entre o profissional, sua atividade laborativa e sua atividade linguageira sobre sua atividade laborativa - não houve rupturas. O que houve foram encadeamentos dialógicos e contínuos que conduziram cada profissional a uma compreensão mais aprofundada sobre a própria atividade concreta de trabalho; sendo ela presente, passada e/ou futura. De acordo com Bakhtin e Volochínov (2010, p. 34), “(...) essa cadeia de criatividade e de compreensão (...), deslocando-se de signo em signo para um novo signo, é única e contínua (...). Em nenhum ponto a cadeia se quebra (...)".

A pesquisadora explorou, na íntegra, todo o corpus discursivo (co)construído durante o processo de realização da pesquisa com o objetivo de confirmar, refutar, destacar e/ou avaliar possíveis convergências e/ou divergências entre o fazer, o dizer e o formar de cada professor formador antes e depois da formação embasada nos princípios clínicos e ergonômicos da atividade que lhes foi proposta.

Em síntese, ela buscou, a partir de uma leitura minuciosa do corpus, analisar e compreender as implicações discursivas e didático-pedagógicas advindas após a intervenção ergonômica e clínica da atividade para a transformação da atividade concreta e/ou linguageira dos dois professores formadores e, potencialmente, para a formação inicial de futuros professores das línguas inglesa e espanhola na UECE.

Para um maior entendimento de todo o processo metodológico, a pesquisadora elaborou um quadro-resumo que apresentamos abaixo:

Tabela 1: Descrição do processo para a (co)construção do corpus discursivo e suas finalidades. Fonte: MAGALHÃ̃ES (2019, p. 135)

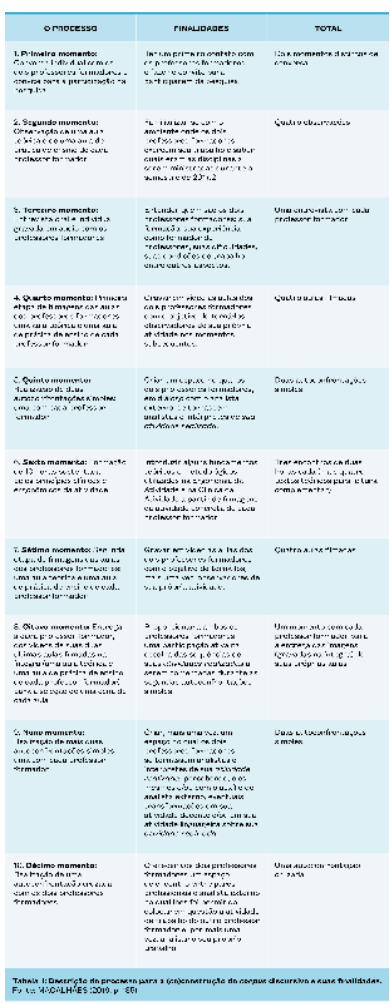

Tabela 1: Descrição do processo para a (co)construção do corpus discursivo e suas finalidades. Fonte: MAGALHÃ̃ES (2019, p. 135) 

alicerçada na filosofia bakhtiniana da linguagem, confirmando, outrossim, uma participação constante e ativa dos sujeitos envolvidos no processo dialógico e (co)analítico configurado para a efetivação da pesquisa aqui apresentada.

De fato, tudo isso retrata uma inovação na formação inicial dos cursos de Letras/Inglês e Letras/Espanhol da UECE. Mais exatamente, foi necessário defender, durante todo o percurso teórico-metodológico adotado, um encadeamento dialógico e (co)analítico sobre formação inicial no qual o professor formador teve um papel central na compreensão e na transformação de sua própria prática formativa (e/ou na prática formativa de seu par profissional).

A seguir, passamos à discussão dos resultados obtidos com a pesquisa apresentada.

\section{Discussão dos resultados}

Destacamos o quanto foi importante para a efetivação da pesquisa em questão o posicionamento de receptibilidade, flexibilidade e coragem de cada professor formador no enfrentamento de suas ações profissionais quotidianas para que fosse possível compreender, juntamente com eles, a construção de sua atividade formativa em sala de aula.

Em outros termos, a disponibilidade e a abertura para analisar, discutir, rever, compreender e, quiçá, modificar suas práticas foi essencial para o processo de construção de um pensar compartilhado sobre os problemas, dificuldades e incertezas do fazer docente em uma instituição pública de ensino voltada para a formação inicial de professores. Com o objetivo de reforçar esse pensamento, citamos Pimenta e Anastasiou (2010) que argumentam a favor da pesquisa da prática (individual e/ou coletiva) docente no ensino superior:

Dá voz ao professor como autor e ator. Favorece uma autocrítica extremamente salutar. Reconstrói a teoria existente. Permite esvaziar os aspectos e ações imediatistas, levando à construção de uma teoria emancipatória: torna os professores mais sujeitos de sua própria história profissional, fomentando a concepção e a implementação de novas alternativas diante do desafio que é ser professor universitário. (Pimenta \& Anastasiou, 2010, p. 199).

De fato, é preciso intensificar esse tipo de pesquisa que parte das próprias práticas profissionais dos professores universitários, ou seja, é somente interrogando-as, descobrindo-as, enfrentando-as, criticando-as, dialogando e refletindo com e sobre elas que os próprios professores formadores poderão enriquecê-las, recriá-las e/ou transformá-las. Nesse sentido, afirmamos que todo o processo teórico-metodológico da pesquisa foi organizado a serviço do estabelecimento de diálogos que propiciaram aos dois professores formadores múltiplas e novas perspectivas de (co)análise e compreensão de seu trabalho na formação inicial.

76 Foi, portanto, no confronto com o "outro" (o próprio professor formador em posição exotópica, o par profissional e/ou a pesquisadora), com suas próprias atividades quotidianas e com os pressupostos teóricos e metodológicos adotados pela Ergonomia da Atividade e pela Clínica da Atividade que a compreensão e a revisão das práticas 
formativas vigentes dos dois professores formadores - bem como das teorias que sustentavam tais práticas - impuseram-se.

Tudo isso se ratifica no excerto extraído da segunda autoconfrontação simples realizada com a professora formadora de inglês, quando, ao ter sido questionada pela pesquisadora [10] (76P: “[...] em que sentido essas sequências foram significativas para você em relação às etapas anteriores da pesquisa [...]?"), a professora formadora de inglês afirma: 79PFI: "Então, é um olhar mais crítico, eu me senti mais ATENTA, vamos dizer assim, que eu observei essas (=) imagens, por tudo que, por todo o processo que a gente já passou, FEZ toda a diferença, seria totalmente diferente se você me jogasse essas imagens para eu assistir [...].Talvez eu não me aprofundasse tanto" [11].

É inegável a importância que a professora formadora conferiu ao processo pelo qual passou para uma compreensão mais cônscia de sua atividade formativa. Ela acredita que, agora, após ter sido parte constituinte e ativa do processo autoconfrontativo e (co)analítico sobre seu próprio trabalho, ela está mais atenta à sua atividade e que a olha de forma diferente em relação a antes (79PFI: “[...] eu me senti mais ATENTA [...], por todo o processo que a gente já passou, FEZ toda a diferença [...]").

Diante disso, convém, nesse momento, citar o próprio Vigotski (1998b) quando ele reivindica um novo método para a psicologia, no início dos anos 1920, "baseado na abordagem materialista dialética da análise da história humana” (Vigotski, 1998b, p. 80):

Em geral, qualquer abordagem fundamentalmente nova de um problema científico leva, inevitavelmente, a novos métodos de investigação e análise. A criação de novos métodos, adequados às novas maneiras de se colocar os problemas, requer muito mais do que uma simples modificação dos métodos previamente aceitos. (Vigotski, 1998b, p. 77).

Relacionando a citação de Vigotski à pesquisa que apresentamos aqui, diríamos que analisar o trabalho docente - algo bem recente dentro do campo da Linguística Aplicada no Brasil (Machado, 2004) - requer, absolutamente, um método que seja apropriado, sobretudo, a entender esse tipo de trabalho como um contínuo movimento no interior da própria história socioprofissional do professor, e não como objeto estável e fixo. Em outros termos, a análise do trabalho docente, no âmbito da Linguística Aplicada, solicita um método que provoque ou crie artificialmente um processo de desenvolvimento - na e pela linguagem - no próprio profissional (Vigotski, 1998b), em seu meio laborativo e/ou na sua atividade (concreta e/ou linguageira); bem como na de seus pares.

81 Mas não apenas isso, podemos, ainda, dizer que, no caso da presente pesquisa, o fato de associar (no sentido de tornar companheiro, parceiro) os dois professores formadores ao trabalho da própria pesquisadora, assim como conhecedores das teorias que sustentam os estudos clínicos e ergonômicos da atividade e do quadro teóricometodológico da autoconfrontação, proporcionou a cada profissional ser um pesquisador ativo e constante do próprio trabalho, bem como rever as próprias teorias de ensino e de formação inicial de professores.

82 Ainda a esse respeito, também constatamos a razão pela qual o quadro teóricometodológico da autoconfrontação é considerado um método indireto histórico $\mathrm{e}$ 
desenvolvimental (Clot, 2011): ele foi capaz, no caso da pesquisa de Magalhães (2019), de interligar o momento presente ao momento passado do profissional sem perder de vista as mudanças futuras projetadas pelo sujeito em sua atividade linguageira.

Em outras palavras, o quadro teórico-metodológico da autoconfrontação abrangeu o processo de desenvolvimento - presente, passado e futuro - (do) profissional dentro de uma perspectiva claramente histórica, social e dialógica. De fato, ele permitiu que o desenvolvimento (do) profissional fosse apreendido "como um processo vivo, e não como um objeto" (Vigotski, 1998b, p. 91). Isso porque ele possibilitou a cada sujeito, no âmbito da pesquisa aqui apresentada, entender o seu trabalho dentro de uma perspectiva (co)analítica, histórica, social e profissional, isto é, dentro de um processo de mudança e na interação verbal com o "outro". Com efeito, tal como afirma Vigotski (1998b), para se compreender um processo, é preciso estudá-lo no interior de um outro processo.

Fundamentalmente, se não tivesse sido possibilitado aos dois professores formadores ver o próprio trabalho no interior de um processo (co)analítico, histórico, social e, acrescentamos, dialógico, provavelmente essa compreensão da professora formadora de inglês sobre seu próprio trabalho não teria sido desencadeada. Em outros termos, se, dentro do processo para a (co)construção do corpus discursivo da referida pesquisa, houvesse sido apenas apresentados aos dois professores formadores os pressupostos teóricos da Ergonomia da Atividade e da Clínica da Atividade, sem relacioná-los diretamente com a atividade formativa dos dois docentes e sem discuti-los de modo conjunto, talvez a professora formadora de inglês não tivesse se dado conta desse seu olhar mais crítico em relação ao seu trabalho no curso de Letras/Inglês da UECE.

Sem esse traçado processual, (co)analítico, dialógico, interativo e histórico evidentemente nas perspectivas da psicologia vigotskiana e da filosofia bakhtiniana da linguagem - não teria sido possível apreender os traços de desenvolvimento presentes na atividade (linguageira e/ou concreta) dos dois professores formadores, sujeitos da pesquisa. Nas palavras de John-Steiner e Souberman (1998, p. 163),

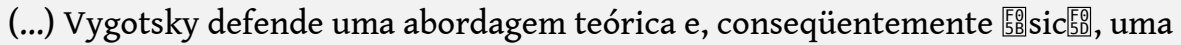
metodologia que privilegia a mudança. $O$ seu esforço de mapear as mudanças ao longo do desenvolvimento deve-se, em parte, à tentativa de mostrar as implicações psicológicas do fato de os homens serem participantes ativos e vigorosos da sua própria existência e de mostrar que, a cada estágio, de seu desenvolvimento, a criança adquire os meios para intervir de forma competente no seu mundo e em si mesma.

E como resultado mais contundente desse desenvolvimento podemos mencionar a organização, por um dos dois professores formadores, de um Fórum de Estágio que reúne, pelo menos uma vez por mês, os professores formadores das disciplinas de Estágio Supervisionado das licenciaturas da UECE (inglês, espanhol, francês e português), com o objetivo de discutir temáticas concernentes a essas disciplinas [12]. O próprio professor formador de espanhol, no momento da autoconfrontação cruzada, discorre sobre a importância desse Fórum: 279PFE: "O Fórum já deu um alento muito BOM. Assim, eu já vejo o pessoal mais RESPIrando [...] a gente PRECISA e o Fórum está fazendo ISSO [...]." 

podemos concluir que foi no interior de um processo ativo do sujeito com sua própria atividade, com os pressupostos teóricos apresentados durante a formação $O$ ensino como trabalho e com os diálogos que foram estabelecidos com outros sujeitos sóciohistoricamente situados sobre as diversas maneiras de realizar o que tem que ser realizado - sendo tudo isso mediado por signos - que cada professor formador se apropriou do seu mundo exterior e se transformou pelo fato mesmo de apropriar-se desse mundo (Brossard, 2012). Enfatizamos que essa apropriação-transformação corresponde ao próprio desenvolvimento (do) profissional. 
93 Falamos de uma transformação provocada por uma compreensão, no entanto, essa transformação partiu de quem (re)organiza as práticas de formação inicial. Daí, a opção pelo quadro teórico-metodológico da autoconfrontação e por uma intervenção nas abordagens clínica e ergonômica da atividade, tendo em vista que estas põem no centro da transformação o próprio profissional e seu trabalho.

Em outras palavras, foi ao (co)analisar suas próprias práticas nos cursos de Letras/ Inglês e Letras/Espanhol, bem como suas experiências vividas no âmbito educativo encetando, desse modo, um debate controverso entre fatores internos e fatores externos, bem como entre teoria e prática - que cada professor formador passou a considerar seu trabalho de uma forma diferente; construindo, por conseguinte, novas formas de compreendê-lo e de realizá-lo. Foi necessário, portanto, “compreender para transformar" (Clot, 2006, p. 102), bem como "transformar para compreender" (Clot \& Faïta, 2000/2016, p. 53), e essa compreensão precisou ser dialógica, na perspectiva de Bakhtin (2015).

Com efeito, um fenômeno, para ser apreendido, precisa ser refletido no interior de uma dinâmica sócio-histórica, ou seja, dentro de um processo em contínuo movimento e mudança (Vigotski, 1998b). Foi, portanto, a participação ativa e constante de cada professor formador em um processo assim engendrado que viabilizou a compreensão e uma eventual transformação de sua própria prática formativa.

Além disso, podemos também referir que o percurso teórico-metodológico elaborado para a concretização da pesquisa foi concebido de maneira que os dois professores formadores realizassem suas (co)análises e compreensões partindo de suas próprias atividades, bem como dos diálogos estabelecidos com o par profissional (e/ou com a pesquisadora) a respeito de tais atividades.

97 Em síntese, foi a partir de uma intervenção nas abordagens clínica e ergonômica da atividade e das relações dialógicas estabelecidas durante o processo autoconfrontativo que foi constatada uma transformação na atividade linguageira dos dois professores a respeito de seu trabalho na formação inicial. Convém, ainda, dizer que, provavelmente, essa transformação irá repercutir nas futuras práticas docentes nos contextos das licenciaturas em Letras/Inglês e Letras/Espanhol da UECE.

98 No entanto, devemos esclarecer que a pesquisa ficou na análise da atividade linguageira do professor formador. As implicações reais (concretas) em seu agir e na formação inicial foram consideradas como potenciais, haja vista que, por razões de cronograma e de prazo para efetuar a referida pesquisa científica, não foi possível para a pesquisadora acompanhar longitudinalmente os professores formadores nem os alunos destes para comprovar em suas práticas pós-pesquisa as transformações que, potencialmente, poderiam vir a ocorrer em seus contextos de atuação profissional. Bakhtin e Volochínov (2010, p. 196) fundamentam esse pensamento ao afirmarem que "É a língua que ilumina a personalidade interior e a consciência, que as cria, diferencia e aprofunda, e não o contrário. O devir da personalidade situa-se na língua (...)”.

99 Concluímos, reconhecendo que a pesquisa de doutorado em questão principiou uma discussão sobre formação inicial docente no interior da qual os professores formadores não apenas tiveram a possibilidade de ver e dialogar com sua própria atividade formativa, mas também conhecer os pressupostos teóricos e metodológicos da pesquisa, associando-se, por conseguinte, aos próprios processos de compreensão- 
transformação e de transformação-compreensão apresentados, respectivamente, pela Ergonomia da Atividade e pela Clínica da Atividade.

\section{BIBLIOGRAFIA}

Amigues, R. (2003). Pour une approche ergonomique de l'activité enseignante. Skholê, hors-série 1, 5-16. http://www.recherches.philippeclauzard.com/ Pour\%20une\%20approche\%20ergonomique\%20de\%20l\%E2\%80\%99activit\%C3\%A9.pdf

Amigues, R. (2004). Trabalho do professor e trabalho de ensino. In A. R. Machado (Org.). o ensino como trabalho: uma abordagem discursiva. (pp. 35-53). Londrina: Eduel.

Bakhtin, M. (2011). Estética da criação verbal. Tradução de Paulo Bezerra. São Paulo: Martins Fontes.

Bakhtin, M. (2015). Problemas da poética de Dostoiévski. Tradução de Paulo Bezerra. Rio de Janeiro: Forense Universitária.

Bakhtin, M., \& Volochínov, V. N. (2010). Marxismo e Filosofia da Linguagem: Problemas Fundamentais do Método Sociológico na Ciência da Linguagem. Tradução de Michel Lahud e Yara Frateschi Vieira. São Paulo: Hucitec.

Brossard, M. (2012). Le développement comme transformation par appropriation des œuvres de la culture. In Y. Clot (Dir.). Vygotsky maintenant. (pp. 95-116). Paris : La Dispute/SNÉDIT.

Clot, Y. (2006). Entrevista: Yves Clot. Cadernos de Psicologia Social do Trabalho, 9(2), 99-107. https:// doi.org/10.11606/issn.1981-0490.v9i2p99-107

Clot, Y. (2008). Travail et pouvoir d'agir. Paris : Presses Universitaires de France.

Clot, Y. (2011). Théorie en clinique de l'activité. In B. Maggi (Dir.). Interpréter l'agir : un défi théorique. (pp.17-39). Paris : Presses Universitaires de France.

Clot, Y., \& Faïta, D. (2000/2016). Gêneros e estilos em análise do trabalho: Conceitos e métodos. Revista Trabalho \& Educação, 25(2), 33-60. https://periodicos.ufmg.br/index.php/trabedu/article/ view/9555/6806

Daniellou, F. (2004). Apresentação à edição brasileira. Tradução de José Marçal Jackson Filho. In F. Daniellou (Coord.). A ergonomia em busca de seus princípios: debates epistemológicos. (pp. VII-X). São Paulo: Edgard Blücher.

Darses, F., \& Montmollin, M. (2006). L'ergonomie. Paris : Éditions La Découverte.

Faïta, D. (1989). Mondes du travail et pratiques langagières. Langages, Parole(s) ouvrière(s), 93, 110-123. https://doi.org/10.3406/lgge.1989.1541

Faïta, D. (2012). L'échange verbal, ressource fondamentale pour la compréhension des activités de travail. Une révision des perspectives ouvertes par le recours au rapport dialogique en analyse de l'activité. Linguagem em Foco: Revista do Programa de Pós-Graduação em Linguística Aplicada da UECE, 4(2), 83- 93. 
Faïta, D., \& Maggi, B. (2007). Un débat en analyse du travail - Deux méthodes en synergie dans l'étude d'une situation d'enseignement. Toulouse : Octarès Éditions.

Farias, A. L. G. (2016). Análise de diálogos de autoconfrontação: relações dialógicas e transformação na atividade linguageira de professores estagiários de francês sobre sua atividade docente. (Tese de Doutoramento). Programa de Pós-Graduação em Linguística Aplicada, Universidade Estadual do Ceará, Fortaleza, Brasil.

Félix, C., \& Saujat, F. (2007). Le développement de l'activité d'une enseignante débutante : les effets du processus d'autoconfrontation dans l'élaboration de ressources opératoires. Colloque formation, apprentissages et développement professionnels des enseignants : outils et méthodes de l'alternance, 1-13, Marseille.

John-Steiner, V., \& Souberman, E. (1998). Posfácio. In L. S. Vigotski, A Formação social da mente: o desenvolvimento dos processos psicológicos superiores. (pp. 161-179). Tradução de José Cipolla Neto, Luís S. Barreto e Solange C. Afeche. São Paulo: Martins Fontes.

Machado, A. R. (2004). Apresentação. In A. R. Machado (Org.). o ensino como trabalho: uma abordagem discursiva. (pp. vii-xx). Londrina: Eduel.

Magalhães, E. M. (2019). Análise dialógica da atividade linguageira de professores formadores de línguas inglesa e espanhola: implicações das abordagens clínica e ergonômica da atividade na formação inicial. (Tese de Doutoramento). Programa de Pós-Graduação em Linguística Aplicada, Universidade Estadual do Ceará, Fortaleza, Brasil.

Magalhães, E. M., \& Moraes, R. M, A. (2016). Autoconfrontação simples (ACS): um instrumento de formação docente. In J. T. Souza et al. (Orgs.) I Coletânea de Teses e Dissertações da UECE. (pp. 154-179). Fortaleza: EdUECE.

Moraes, R. M. A., \& Magalhães, E. M. (2017). Abordagem clínica na análise da atividade docente: uma via unindo pesquisa, intervenção e formação. Revista Horizontes, 35(3), 105-120. DOI: https:// doi.org/10.24933/horizontes.v35i3.515

Pimenta, S. G., \& Anastasiou, L. G. C. (2010). Docência no ensino superior. São Paulo: Cortez.

Sobral, A., \& Giacomelli, K. (2018). Das significações na língua ao sentido na linguagem: parâmetros para uma análise dialógica. Linguagem em (Dis)curso, 18(2), 307-322. DOI: http:// dx.doi.org/10.1590/1982-4017-180203-9317

Souza-e-Silva, M. C. P. (2004). O ensino como trabalho. In A. R. Machado (Org.). 0 ensino como trabalho: uma abordagem discursiva. (pp. 81-104). Londrina: Eduel.

Vigotski, L. S. (1998a). Pensamento e Linguagem. Tradução de Jefferson L. Camargo. São Paulo: Martins Fontes.

Vigotski, L. S. (1998b). A formação social da mente: o desenvolvimento dos processos psicológicos superiores. Tradução de José Cipolla Neto, Luís S. M. Barreto e Solange C. Afeche. São Paulo: Martins Fontes.

Voloshinov, V. N., \& Bakhtin, M. (1976). Discurso na vida e discurso na arte (sobre poética sociológica). In V. N. Voloshinov, Freudism. (pp. 1-25). Tradução de Carlos A. Faraco e Cristóvão Tezza. New York: Academic Press. 


\section{NOTAS}

1. Ressaltamos que os dois professores formadores aceitaram participar da pesquisa de forma livre e esclarecida, de acordo com o parecer consubstanciado final do Comitê de Ética em Pesquisa da Universidade Estadual do Ceará de número 2.560.179 e CAAE 84849618.2.0000.5534.

2. Para Farias (2016, p. 104, grifo da autora), atividade linguageira "[...] é uma atividade sociodiscursiva e interacional de produção de sentido (voltada, nesse caso, para o objeto atividade de trabalho)."

3. Uma visão externa do profissional em relação às situações concretas de seu próprio trabalho.

4. Segundo Daniellou (2004, p. IX), “Intervir não é somente colocar em circulação as análises da atividade, [...], mas engajar-se pessoalmente nos processos de ação que comportam vários atores. [...] Intervir é participar na construção de compromissos, na criação de margens de manobra, na elaboração da mudança". É baseando-nos nesta reflexão que entendemos a pesquisa que aqui apresentamos como uma pesquisa-intervenção.

5. Como marcas linguísticas, entendemos os elementos do próprio sistema abstrato, formal e estabilizado da língua (elementos morfológicos, sintáticos, gramaticais, etc.) e como marcas enunciativas, "as realidades do sistema do uso" (Sobral \& Giacomelli, 2018, p. 312), isto é, os elementos sócio-ideológico-culturais que compõem a realidade de uma interação entre sujeitos cultural e historicamente situados.

6. Sequências são trechos de aulas filmadas, previamente selecionados pela pesquisadora e/ou pelos sujeitos participantes da pesquisa, e submetidos à visualização, bem como aos comentários destes últimos durante a realização das sessões de autoconfrontações (simples e cruzada).

7. Intitulamos a formação ofertada aos dois professores formadores de $O$ ensino como trabalho em razão do livro 0 ensino como trabalho, organizado por Machado (2004), ter sido uma obra fundamental e inspiradora para o conhecimento e a divulgação da abordagem ergonômica da atividade docente em território brasileiro.

8. Tentamos, conforme o tempo que tínhamos disponível para a formação, ou seja, 10h/a, apresentar o máximo possível dos principais fundamentos que guiam os estudos da Ergonomia da Atividade e da Clínica da Atividade.

9. Compreendemos o termo "complexo" no sentido de os diálogos produzidos nesse momento do processo se tratarem de uma segunda atividade linguageira sobre uma primeira. Ou seja, no momento da autoconfrontação cruzada, o profissional encontra-se diante de imagens de situações concretas de seu trabalho e de comentários que ele mesmo produziu sobre essas situações no momento da autoconfrontação simples; por conseguinte, há a possibilidade de uma verbalização de novos comentários sobre os já existentes.

10. A sigla $\underline{\mathrm{PFI}}$ refere-se à professora formadora de inglês, $\underline{\mathrm{PFE}}$ ao professor formador de espanhol e $\underline{P}$ à pesquisadora.

11. Na pesquisa que aqui apresentamos foi adotada uma abordagem Metalinguística (Bakhtin, 2015) para a realização das transcrições. Desse modo, as hesitações, as pausas, os silêncios, as ênfases, etc. dos professores formadores e da pesquisadora foram levados em consideração. A

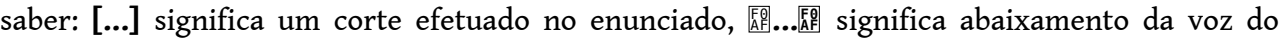
sujeito, (=) significa letras, sílabas ou palavras repetidas.

12. A ideia do professor formador de espanhol, durante o processo da (co)construção do corpus da pesquisa, foi a de reunir todos os professores formadores das disciplinas de Estágio Supervisionado da UECE, pelo menos uma vez por mês, para conversar sobre temáticas relacionadas à essas disciplinas, como por exemplo, os conteúdos programáticos, os relatórios finais, as observações obrigatórias e a regência. 


\section{RESUMOS}

Este trabalho propõe-se a apresentar o processo metodológico adotado numa pesquisa de doutorado realizada com dois professores formadores da Universidade Estadual do Ceará (UECE). Para a (co)construção do corpus discursivo, a investigadora recorreu a diálogos produzidos ao longo do processo teórico-metodológico da autoconfrontação, assim como a uma formação continuada de 10 horas guiada pelas abordagens clínica e ergonômica da atividade. Essa opção metodológica permitiu refletir sobre como pode ser construído, juntamente com os protagonistas da atividade, o corpus de uma pesquisa-intervenção alicerçada nos princípios do dialogismo bakhtiniano e na teoria histórico-cultural vigotskiana sobre o desenvolvimento humano. Concluímos que um fenômeno, para ser apreendido, precisa ser refletido no interior de uma dinâmica sócio-histórica e que a participação ativa e constante de cada profissional em um processo autoconfrontativo (co)analítico viabilizaria uma maior compreensão da atividade laborativa, mobilizando sua recriação e/ou transformação.

Este trabajo tiene por finalidad presentar el proceso metodológico adoptado en una investigación doctoral realizada con dos profesores formadores dela Universidad Estadual de Ceará (UECE). Para la (co)construcción del corpus discursivo, la investigadora decidió usar diálogos producidos a lo largo del proceso teórico-metodológico de autoconfrontación, así como una formación continua de 10 horas guiada por los abordajes clínico y ergonómico de la actividad. Esa opción metodológica permitió reflexionar sobre cómo puede ser construido, en colaboración con los protagonistas de la actividad, el corpus de una investigación-intervención basada en los principios del dialogismo bakhtiniano y en la teoría histórico-cultural vigotskiana acerca del desarrollo humano. Hemos concluido que un fenómeno, para ser aprehendido, necesita ser reflexionado en el interior de una dinámica sociohistórica y que la participación activa y constante de cada profesional en un proceso de autoconfrontación (co)analítico permitiría una mayor comprensión de la actividad laboral, movilizando su recreación y/o transformación.

L'objectif de ce travail est de présenter le processus méthodologique adopté lors d'une recherche de doctorat réalisée avec deux professeurs formateurs de l'Université de l'État du Ceará (UECE). Pour la production du corpus discursif, l'option a été de recourir à des dialogues produits durant le processus théorique-méthodologique de l'autoconfrontation, ainsi qu'à une formation en continu de 10 heures, guidée par les approches clinique et ergonomique de l'activité. Cette option méthodologique a permis d'analyser comment on peut construire, en partenariat avec les protagonistes de l'activité, le corpus d'une recherche-intervention fondée sur les principes du dialogisme bakhtinien et aussi sur la théorie historique-culturelle vigotskienne à propos du développement humain. On en a conclu qu'un phénomène, pour être compris, doit être réfléchi au sein d'une dynamique socio-historique et que la participation active et continue de chaque professionnel dans un processus autoconfrontatif (co)analytique permettrait une meilleure compréhension de l'activité de travail, mobilisant sa recréation et/ou transformation.

This paper aims to present the methodological process adopted in a doctoral research (Magalhães, 2019) carried out with two language teacher educators at the State University of Ceará (UECE). In order to (co)construct the discursive corpus, the researcher resorted to the selected dialogues produced during the theoretical-methodological process of self-confrontation, as well as to a 10-hour training course carried out based on the assumptions of the clinical and ergonomic activity approaches. The chosen methodology allowed some reflection on how corpus construction can be made, along with its protagonists, in an interventional research based on the principles of Bakhtinian dialogism and Vigotskian cultural-historical theory of human 
development. We conclude that, to be detected, a phenomenon needs to be reflected within a socio-historical dynamic; also, the active and constant participation of each professional in a selfconfrontational (co)analytical process would enable a greater understanding of work activity, mobilizing its recreation and/or its transformation.

ÍNDICE

Palabras claves: ergonomía de la actividad, clínica de la actividad, autoconfrontación, coanálisis de la actividad

Keywords: ergonomics activity, clinic of activity, self-confrontation, activity co-analysis Palavras-chave: ergonomia da atividade, clínica da atividade, autoconfrontação, coanálise da atividade

Mots-clés: ergonomie de l'activité, clinique de l'activité, autoconfrontation, coanalyse de l'activité

\section{AUTORES}

\section{ELISANDRA MARIA MAGALHÃES}

Casa de Cultura Francesa, Centro de Humanidades da Universidade Federal do Ceará; Av. da Universidade, 2683 - Benfica, CEP 60020-181, Fortaleza - CE, Brasil elisandra.magalhaes@ufc.br

\section{DANIEL FAÏTA}

Aix Marseille Université, UR 4671, ADEF; 245 J route de Roquefraîche, 84360 Lauris, France danielfaita13@gmail.com 